\title{
Role of endogenous endothelin on coronary reflow after cardioplegic arrest
}

Andrew T. Goodwin, FRCS

Ryszard T. Smolenski, PhD

Caroline C. Gray, MSc

Jay Jayakumar, FRCS

Mohamed Amrani, PhD, FRCS

Magdi H. Yacoub, FRS, FRCP, FRCS
From the Department of Cardiac Surgery, Royal Brompton and Harefield NHS Trust, Heart Science Centre, Harefield Hospital, Middlesex, United Kingdom.

Read at the 73rd Scientific Sessions of the American Heart Association, New Orleans, La, November 12-15, 2000.

Received for publication Nov 6, 2000; revisions requested Jan 3, 2001; revisions received Feb 9, 2001; accepted for publication Feb 28, 2001.

Address for reprints: Professor Sir M. H. Yacoub, Department of Cardiac Surgery, Royal Brompton and Harefield NHS Trust, Heart Science Centre, Harefield Hospital, Middlesex UB9 6JH, United Kingdom (Email: GoodwinAT@ hotmail.com).

J Thorac Cardiovasc Surg 2001;122:1167-73

Copyright (c) 2001 by The American Association for Thoracic Surgery

0022-5223/2001 $\$ 35.00+0 \quad \mathbf{1 2 / 1 / 1 1 5 4 2 7}$

doi:10.1067/mtc.2001.115427
Objective: Endothelin plays a role in the regulation of basal coronary tone. We hypothesized that low coronary reflow and reduced cardiac function after prolonged ischemia may be due to increased release of endogenous endothelin.

Methods: Using an isolated perfused rat heart, we examined the effect of the addition of various endothelin antagonists during reperfusion after 4 hours of cardioplegic arrest at $4{ }^{\circ} \mathrm{C}$. Hearts were freeze-clamped at the end of reperfusion for analysis of high-energy phosphate levels. Results are expressed as the percentages of preischemic values.

Results: The addition of bosentan or Ro61-0612 (nonselective endothelin antagonists) resulted in a significant increase in the recovery of coronary flow after 30 minutes of reperfusion $(100.9 \%$ vs $85.3 \%[P=.03]$ and $122.4 \%$ vs $83.7 \%[P<$ $.001]$, respectively, versus controls). The addition of PD155080 (endothelin A antagonist) had a similar effect (129.5\% vs $91.4 \%, P=.008)$. BQ788 (endothelin B antagonist) and phosphoramidon (endothelin-converting enzyme inhibitor) had no effect. Myocardial adenosine triphosphate levels were significantly (12.1\%) higher after reperfusion with Ro61-0612 (18.1 $\pm 0.4 \mu \mathrm{mol} / \mathrm{g}$ vs $16.2 \pm 0.5 \mu \mathrm{mol} / \mathrm{g}, P=.01)$. There was no difference in the recovery of cardiac mechanical function with any of the antagonists studied.

Conclusion: These results suggest that endogenous endothelin plays a role in low coronary reflow after prolonged cardioplegic arrest but does not impair recovery of myocardial function.

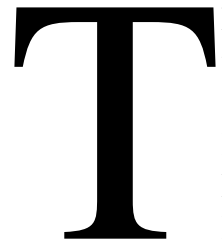

he endothelium plays a major role in the maintenance of vascular tone through the production and metabolism of various vasodilating and vasoconstricting substances, including nitric oxide and endothelin (ET). We have recently demonstrated that endogenous release of ET plays an important role in basal coronary tone in the rat. ${ }^{1}$ Ischemia-reperfusion injury results in a decrease in cardiac function and reduced coronary flow (CF; or low coronary reflow). It has been shown the vascular endothelium plays an important role in low coronary reflow through the release of various vasoactive substances, particularly nitric oxide. ${ }^{2-4}$

Previous studies using models of warm ischemia have shown that ET levels are elevated after myocardial infarction and that ET antagonists and monoclonal antibodies to ET can reduce the size of infarction..$^{5-9}$ However, other studies have found no effect of ET antagonists on the size of infarction or on the recovery of cardiac function after ischemia. ${ }^{10,11}$ We have shown previously that inhibition of ET during cold ischemia, by means of the addition of antagonists to cardioplegic solution, can 
TABLE 1. Baseline preischemic variables for each group of experiments

\begin{tabular}{|c|c|c|c|c|c|c|c|c|c|c|}
\hline & \multicolumn{3}{|c|}{ Langendorff mode } & \multicolumn{7}{|c|}{ Working mode } \\
\hline & $\mathbf{n}$ & $\mathrm{CF}(\mathrm{mL} / \mathrm{min})$ & Significance & $\mathrm{n}$ & $\mathrm{AF}(\mathrm{mL} / \mathrm{min})$ & $\mathrm{CF}(\mathrm{mL} / \mathrm{min})$ & $\mathrm{CO}(\mathrm{mL} / \mathrm{min})$ & $\operatorname{PAP}\left(\mathrm{cm} \mathrm{H}_{2} \mathrm{O}\right)$ & $\mathrm{dP} / \mathrm{dt}$ & Significance \\
\hline Control & 6 & $12.3 \pm 1.9$ & & 6 & $27.3 \pm 8.6$ & $24.3 \pm 9.3$ & $51.7 \pm 6.7$ & $159 \pm 19$ & $18.7 \pm 5.3$ & \\
\hline PD155080 & 6 & $13.6 \pm 1.6$ & NS & 6 & $24.6 \pm 8.0$ & $25.8 \pm 7.2$ & $50.4 \pm 6.6$ & $150 \pm 11$ & $12.3 \pm 4.5$ & All NS \\
\hline Control & 6 & $12.5 \pm 2.0$ & & 5 & $25.3 \pm 4.8$ & $24.0 \pm 1.5$ & $49.3 \pm 6.1$ & $200 \pm 39$ & $75.8 \pm 20.6$ & \\
\hline Ro61-0612 & 6 & $12.3 \pm 1.3$ & NS & 5 & $20.4 \pm 9.4$ & $25.7 \pm 1.5$ & $46.1 \pm 9.8$ & $160 \pm 30$ & $62.8 \pm 24.0$ & All NS \\
\hline Control & 15 & $11.3 \pm 1.5$ & & 6 & $27.0 \pm 8.2$ & $26.4 \pm 4.5$ & $53.4 \pm 10.1$ & $147 \pm 22$ & $13.3 \pm 8.3$ & \\
\hline Bosentan & 15 & $11.8 \pm 1.7$ & NS & 6 & $31.3 \pm 6.7$ & $26.4 \pm 5.2$ & $57.8 \pm 7.1$ & $158 \pm 12$ & $16.3 \pm 4.1$ & All NS \\
\hline Control & 6 & $11.8 \pm 1.0$ & & 5 & $27.4 \pm 8.6$ & $21.4 \pm 4.7$ & $48.8 \pm 12.8$ & $155 \pm 19$ & $19.2 \pm 10.1$ & \\
\hline B0788 & 6 & $11.6 \pm 2.0$ & NS & 5 & $34.2 \pm 7.3$ & $28.2 \pm 5.7$ & $62.4 \pm 9.2$ & $158 \pm 7$ & $13.6 \pm 3.8$ & All NS \\
\hline Control & 5 & $13.2 \pm 1.2$ & & 10 & $25.9 \pm 8.4$ & $23.1 \pm 5.1$ & $49.0 \pm 12.1$ & $164 \pm 23$ & $74.2 \pm 27.5$ & \\
\hline Phosphoramidon & 5 & $13.0 \pm 1.1$ & NS & 8 & $23.3 \pm 4.9$ & $24.8 \pm 6.3$ & $48.0 \pm 3.9$ & $153 \pm 19$ & $64.5 \pm 27.2$ & All NS \\
\hline
\end{tabular}

Values are given as means \pm standard deviation. Significance is shown versus each respective control group. $C F$, Coronary flow; $A F$, aortic flow; $P A P$, peak aortic pressure; $N S$, not significant.

Low Coronary Reflow:

\begin{tabular}{|c|c|c|}
\hline Krebs & Ischaemia $4^{\circ} \mathrm{C}$ & $\begin{array}{c}\text { Krebs } \\
\text { or } \\
\text { Drug }+ \text { Krebs }\end{array}$ \\
\hline$\approx 15$ mins & 4 hours & 30 mins
\end{tabular}

Working Mode:

\begin{tabular}{|c|l|c|c|c|}
\hline Krebs & Krebs & Ischaemia $4^{\circ} \mathrm{C}$ & $\begin{array}{c}\text { Krebs } \\
\text { or } \\
\text { Drug + Krebs } \\
\text { (LM) }\end{array}$ & Krebs \\
(LM) & (WM) & & (WM) \\
\hline 15 mins & 15 mins & 4 hours & 15 mins & 15 mins \\
\hline
\end{tabular}

Figure 1. Experimental time course. Shaded area corresponds to period of cardioplegic arrest at $4^{\circ} \mathrm{C}$. $L M$, Langendorff mode; $W M$, working mode.

be beneficial in the recovery of postischemic $\mathrm{CF}$ in a protocol mimicking the conditions of preservation during cardiac operations and transplantation. ${ }^{12}$ However, there was no benefit in the recovery of cardiac mechanical function. To date, there are no studies of the role of endogenous ET in low coronary reflow after hypothermic or prolonged ischemia.

In view of the uncertainty of the role of ET during reperfusion, and in particular during prolonged cardioplegic arrest, the aim of this study was to examine the role of endogenous ET in the postischemic reduction of $\mathrm{CF}$ and cardiac function.

\section{Material and Methods Animals}

Male Sprague-Dawley rats weighing 300 to $330 \mathrm{~g}$ were used in all experiments. In all studies, animals received humane care in compliance with the "Principles of Laboratory Animal Care" formulated by the National Society for Medical Research and the "Guide for the Care and Use of Laboratory Animals" prepared by the Institute of Laboratory Animal Resources, National Research Council, and published by the National Academy Press, revised 1996.

\section{Experimental Preparation}

The isolated working rat heart preparation was used in this study, as has already been described in detail elsewhere. ${ }^{12,13}$ In brief, the animals were put to death by means of cervical dislocation. The femoral vein was immediately exposed, and heparin (200 IU) was injected. The heart was then excised and immediately placed in ice-cold $\left(4^{\circ} \mathrm{C}\right) \mathrm{Krebs}$ solution. The aorta was rapidly cannulated (within approximately 30 seconds), and Langendorff perfusion was initiated. The hearts were perfused with Krebs-Henseleit bicarbonate buffer consisting of the following: $\mathrm{NaCl}, 118.5$ $\mathrm{mmol} / \mathrm{L} ; \mathrm{NaHCO}_{3}, 25.0 \mathrm{mmol} / \mathrm{L} ; \mathrm{KCl}, 4.8 \mathrm{mmol} / \mathrm{L} ; \mathrm{MgSO}_{4}, 1.2$ $\mathrm{mmol} / \mathrm{L} ; \mathrm{KH}_{2} \mathrm{PO}_{4}, 1.2 \mathrm{mmol} / \mathrm{L} ; \mathrm{CaCl}_{2}, 2.25 \mathrm{mmol} / \mathrm{L}$; and glucose, $11.0 \mathrm{mmol} / \mathrm{L}$. The buffer is continuously gassed with $95 \%$ oxygen and $5 \%$ carbon dioxide, maintained at $37^{\circ} \mathrm{C}$ and $\mathrm{pH} 7.4$, and flows from a reservoir $100 \mathrm{~cm}$ above the heart.

In the hearts used in the working mode, the left atrium is then cannulated. An incision is also made in the pulmonary artery to ensure ejection of the coronary sinus effluent. After an initial period of Langendorff perfusion, the heart is switched over to the working mode. The left atrium is perfused at a constant pressure of $15 \mathrm{~cm} \mathrm{H}_{2} \mathrm{O}$ from a reservoir $15 \mathrm{~cm}$ above the atrial cannula. The heart then spontaneously ejects the perfusion fluid through the aortic cannula against a pressure of $100 \mathrm{~cm} \mathrm{H}_{2} \mathrm{O}$ (the height of the aortic flow $[\mathrm{AF}]$ line). The heart is suspended in a water-jacketed chamber maintained at $37^{\circ} \mathrm{C}$.

$\mathrm{CF}$ during Langendorff perfusion was monitored with an inline electromagnetic flow probe (ECM2 $20 \mathrm{~mL}$; Scalar, Delft, Holland) connected to its compatible flowmeter (MDL 1401, Scalar). This provided an accurate $(0.0-40.0 \mathrm{~mL} / \mathrm{min})$ digital readout of mean $\mathrm{CF}$, with a simultaneous hard copy recording through a connection with a chart recorder (RS3400; Gould Electronics, Hainault, Essex, United Kingdom). This allowed accurate moni- 

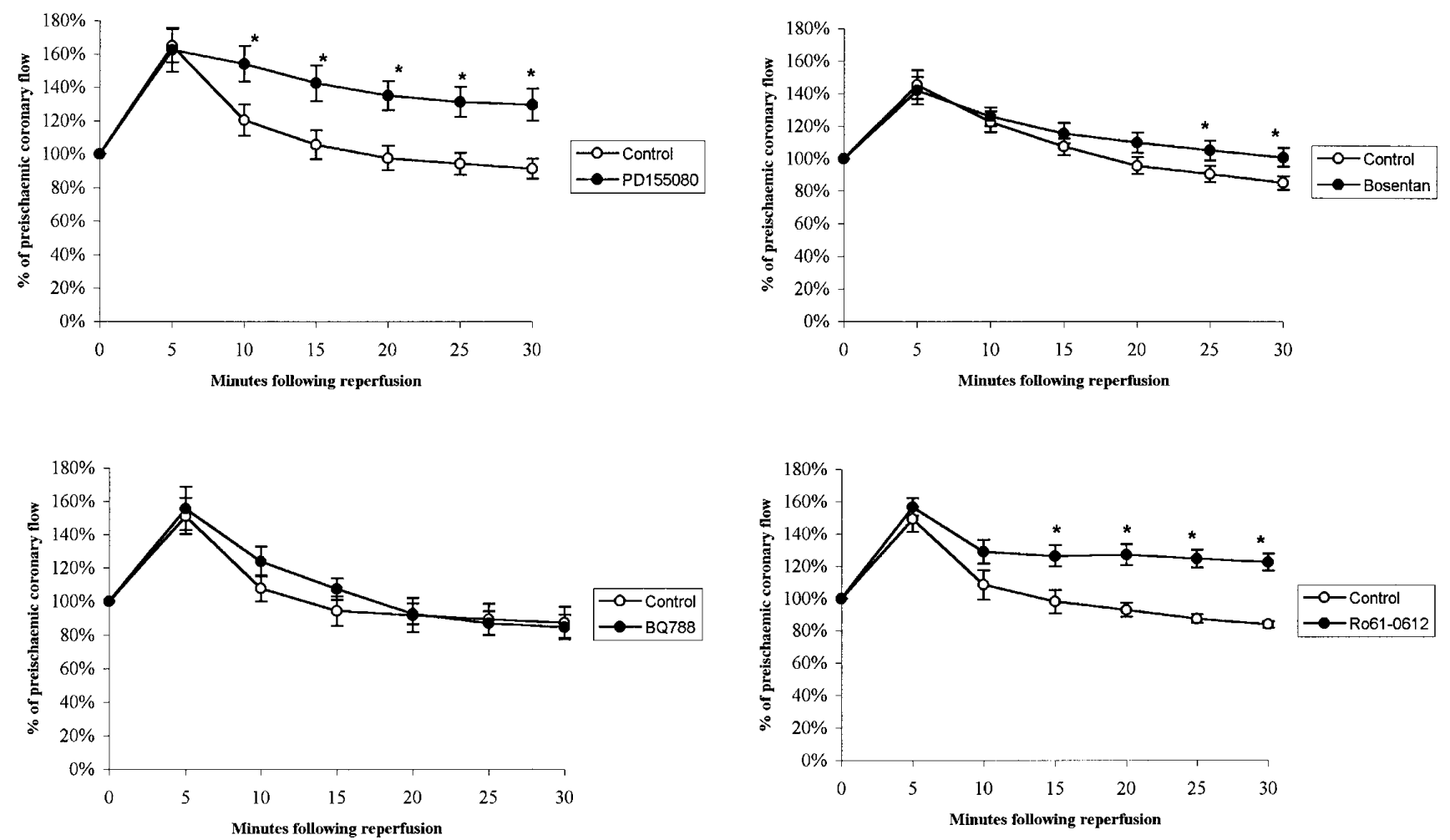

Figure 2. Effect of different ET antagonists (bosentan and Ro61-0612 $=\operatorname{mixed} E T_{A} / E_{B} ; P D 155080=E T_{A} ; B 0788=$ $\mathrm{ET}_{\mathrm{B}}$ ) on recovery of CF after 4 hours' cardioplegic arrest at $4^{\circ} \mathrm{C} .{ }^{*} P<.05$ versus control.

toring of steady-state conditions (less than $0.1 \mathrm{~mL} / \mathrm{min}$ change in $\mathrm{CF}$ over 3 minutes). While the heart was in working mode, the AF was measured by means of an electromagnetic flow probe (ECM2 $100 \mathrm{~mL}$, Scalar). This allowed measurement of flows from 0 to 100 $\mathrm{mL} / \mathrm{min}$. CF (during working mode) was recorded by means of timed collection of the coronary sinus effluent into a measuring cylinder. Cardiac output is taken as the sum of AF and CF. Aortic pressure is measured with a transducer, and a simultaneous hard copy is made (as above). From this, $\mathrm{dP} / \mathrm{dt}$ is computed.

Ischemic cardioplegic arrest may be achieved by infusing 10 $\mathrm{mL}$ of St Thomas' Hospital No. 1 solution (made up in $1 \mathrm{~L}$ of Ringer's lactate solution) at $4{ }^{\circ} \mathrm{C}$ through the side arm of the aortic cannula from a reservoir $60 \mathrm{~cm}$ above the heart. The heart is then maintained immersed in cardioplegic solution at $4{ }^{\circ} \mathrm{C}$ for 4 hours. This protocol mimics conditions of the donor heart undergoing cardiac transplantation.

\section{Drugs and Chemicals}

The drugs used in this experiment were all made up to the required concentration in the Krebs buffer. The drugs used were bosentan (Ro47-0203, 10 $0^{-5} \mathrm{~mol} / \mathrm{L}$; Hoffmann-La Roche Ltd, Basel, Switzerland), a mixed $\mathrm{ET}_{\mathrm{A}} / \mathrm{ET}_{\mathrm{B}}$ antagonist; Ro61-0612 (10 ${ }^{-5}$ mol/L, Hoffmann-La Roche), a mixed $\mathrm{ET}_{\mathrm{A}} / \mathrm{ET}_{\mathrm{B}}$ antagonist; PD155080 (10 ${ }^{-4} \mathrm{~mol} / \mathrm{L}$; Parke-Davis Pharmaceuticals, Ann Arbor, Mich), a selective $\mathrm{ET}_{\mathrm{A}}$ receptor antagonist; BQ788 (10 ${ }^{-5} \mathrm{~mol} / \mathrm{L}$, Parke-Davis), a selective $\mathrm{ET}_{\mathrm{B}}$ antagonist; and phosphoramidon $\left(10^{-5} \mathrm{~mol} / \mathrm{L}\right.$; Sigma, Poole, Dorset, United Kingdom), an endothelin-converting enzyme (ECE) inhibitor. The concentrations used were chosen after previous similar experiments in which doseresponse studies were performed. ${ }^{1}$

\section{Experimental Time Course}

Data on the experimental time course are shown in Figure 1.

Low coronary reflow. After excision of the heart, Langendorff perfusion was commenced with Krebs solution. When steady-state $\mathrm{CF}$ was achieved, the hearts underwent 4 hours of cardioplegic arrest at $4^{\circ} \mathrm{C}$. After ischemia, the hearts were randomly reperfused with either the drug (experimental group) or Krebs solution (control group) for 30 minutes (or 60 minutes in the case of phosphoramidon). The longer perfusion time for phosphoramidon was chosen because it acts by inhibiting the conversion of big ET to ET. In a study on human forearm blood flow, a maximum response to phosphoramidon was seen at 60 minutes. ${ }^{14}$ Separate controls were used for each drug. $\mathrm{CF}$ was recorded at 5-minute intervals.

Working mode. After excision of the heart, Langendorff perfusion was commenced with Krebs solution. After 15 minutes, the heart was switched to working mode. At the end of 15 minutes of working mode, $\mathrm{CF}, \mathrm{AF}$, cardiac output, peak aortic pressure, and $\mathrm{dP} / \mathrm{dt}$ were recorded. The hearts then underwent 4 hours of cardioplegic arrest at $4^{\circ} \mathrm{C}$. After ischemia, the hearts were reperfused with either the drug (experimental group) or Krebs solution (control group) for 15 minutes in Langendorff mode. Separate controls were 


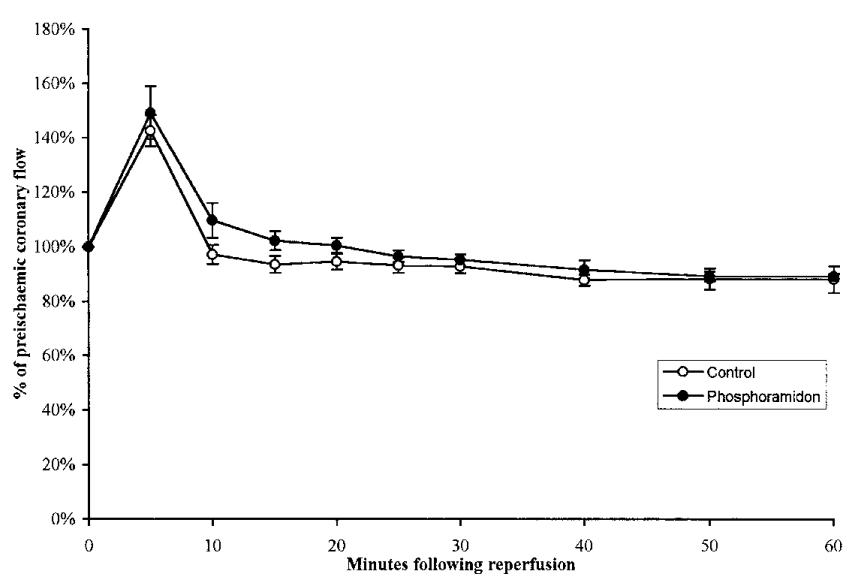

Figure 3. Effect of phosphoramidon (ECE inhibitor) given during 60 minutes of reperfusion on the recovery of CF after 4 hours' cardioplegic arrest.

used for each drug. After this period of Langendorff perfusion, the heart was switched back to working mode for a further 15 minutes. At the end of this period, the same parameters as before were measured (CF, AF, cardiac output, peak aortic pressure, and dP/dt).

\section{High-Performance Liquid Chromatography Analysis}

In the experiment measuring low coronary reflow after the addition of Ro61-0612, the hearts were freeze-clamped at the end of reperfusion. The corresponding control hearts (ie, hearts reperfused with plain Krebs solution) were also freeze-clamped at the end the experiment. Tissue extracts were prepared from freeze-dried hearts with $0.6 \mathrm{~mol} / \mathrm{L}$ perchloric acid $(25 \mu \mathrm{L} / \mathrm{mg}$ dry tissue $)$. The extracts were then centrifuged $\left(13,000 \mathrm{~g}\right.$ for 3 minutes at $\left.4^{\circ} \mathrm{C}\right)$, and the supernatant was neutralized with $2 \mathrm{~mol} / \mathrm{L} \mathrm{KOH}$. All determinations of metabolite concentrations were performed with high-performance liquid chromatography by means of a Merck-Hitachi chromatograph (Darmstadt, Germany), as described previously. ${ }^{15-17}$

\section{Expression of Results}

$\mathrm{CF}, \mathrm{AF}$, and cardiac output were recorded in milliliters per minute. Peak aortic pressure was recorded in centimeters of $\mathrm{H}_{2} \mathrm{O}$. CFs are expressed as a percentage of the initial (preischemic) steady-state CF. In the working mode hearts the postischemic values of cardiac output, peak aortic pressure, and $\mathrm{dP} / \mathrm{dt}$ are expressed as a percentage of the preischemic values. Data were compared by analysis of variance, followed by a Bonferroni test for multiple comparisons to indicate differences between groups.

\section{Results}

\section{Low Coronary Reflow}

Data on low coronary reflow are shown in Figures 2 and 3. Baseline preischemic $\mathrm{CF}$ for each experimental group is shown in Table 1. During reperfusion, there was a consistent decrease in $\mathrm{CF}$ in control animals to approximately $85 \%$ to $90 \%$ of preischemic flow. Reperfusion after the addition of the combined $\mathrm{ET}_{\mathrm{A}} / \mathrm{ET}_{\mathrm{B}}$ antagonists bosentan or Ro61-0612
TABLE 2. Metabolite concentrations of the heart after 4 hours' cardioplegic arrest at $4^{\circ} \mathrm{C}$ and reperfusion with either Ro61-0612 or Krebs solution (controls)

\begin{tabular}{lcc}
\hline Metabolite & $\begin{array}{c}\text { Control (umol/g } \\
\text { dry weight) }\end{array}$ & $\begin{array}{c}\text { Ro61-0612 (umol/g } \\
\text { dry weight) }\end{array}$ \\
\hline GTP & $0.99 \pm 0.01$ & $1.04 \pm 0.02$ \\
GDP & $0.24 \pm 0.01$ & $0.22 \pm 0.01$ \\
GMP & $0.22 \pm 0.06$ & $0.24 \pm 0.03$ \\
IMP & $0.01 \pm 0.01$ & $0.01 \pm 0.01$ \\
ATP & $16.19 \pm 0.51$ & $18.14 \pm 0.39^{*}$ \\
ADP & $3.47 \pm 0.20$ & $3.28 \pm 0.08$ \\
AMP & $0.29 \pm 0.02$ & $0.25 \pm 0.02$ \\
ADPR & $0.13 \pm 0.01$ & $0.13 \pm 0.01$ \\
Hypoxanthine & $0.04 \pm 0.01$ & $0.04 \pm 0.01$ \\
Xanthine & $0.06 \pm 0.03$ & $0.09 \pm 0.03$ \\
NADP & $0.55 \pm 0.01$ & $0.49 \pm 0.09$ \\
NAD & $3.95 \pm 0.05$ & $4.13 \pm 0.08$ \\
Uridine & $0.001 \pm 0.001$ & $0.001 \pm 0.001$ \\
Inosine & $0.08 \pm 0.01$ & $0.09 \pm 0.01$ \\
Adenosine & $0.01 \pm 0.0$ & $0.02 \pm 0.01$ \\
\hline
\end{tabular}

$\overline{G T P}$, Guanosine triphosphate; GDP, guanosine diphosphate; GMP, guanosine monophosphate; $I M P$, inosine 5 -monophosphate; $A D P$, adenosine diphosphate; $A M P$, adenosine monophosphate; $A D P R$, adenosine diphosphate ribose; NADP, nicotinamide adenine dinucleotide phosphate; $N A D$, nicotinamide adenine dinucleotide.

${ }^{*} P=.01$ versus control hearts.

reversed this decrease and resulted in a further significant increase in the recovery of postischemic CF $(100.9 \%$ vs $85.3 \%[P=.03]$ and $122.4 \%$ vs $83.7 \%[P<.001]$, respectively, vs control hearts at 30 minutes of reperfusion). The addition of the selective $\mathrm{ET}_{\mathrm{A}}$ antagonist PD155080 had a similar effect $(129.5 \%$ vs $91.4 \%[P=.008])$. However, the addition of $\mathrm{BQ788}\left(\mathrm{ET}_{\mathrm{B}}\right.$ antagonist; $84.7 \%$ vs $87.4 \%$ ) and phosphoramidon (ECE inhibitor; $89.4 \%$ vs $88.3 \%$ at 60 minutes of reperfusion) had no effect on the recovery of CF.

\section{Recovery of Cardiac Mechanical Function}

Data on recovery of cardiac mechanical function are shown in Figure 4. Baseline preischemic values for each of the groups are shown in Table 1. When each antagonist was compared with control solution, there was no significant difference in the recovery of any of the parameters (cardiac output, peak aortic pressure, and $\mathrm{dP} / \mathrm{dt}$ ) of cardiac mechanical function. Likewise, the ECE inhibitor phosphoramidon had no effect on the recovery of mechanical function.

\section{High-Performance Liquid Chromatography}

The results of the various metabolites measured are shown in Table 2. There was a significant increase in adenosine triphosphate (ATP) levels by $12.1 \%$ after reperfusion with Ro61-0612 ( $\mathrm{ET}_{\mathrm{A}} / \mathrm{ET}_{\mathrm{B}}$ antagonist) compared with that seen in control hearts. There were no significant differences in 

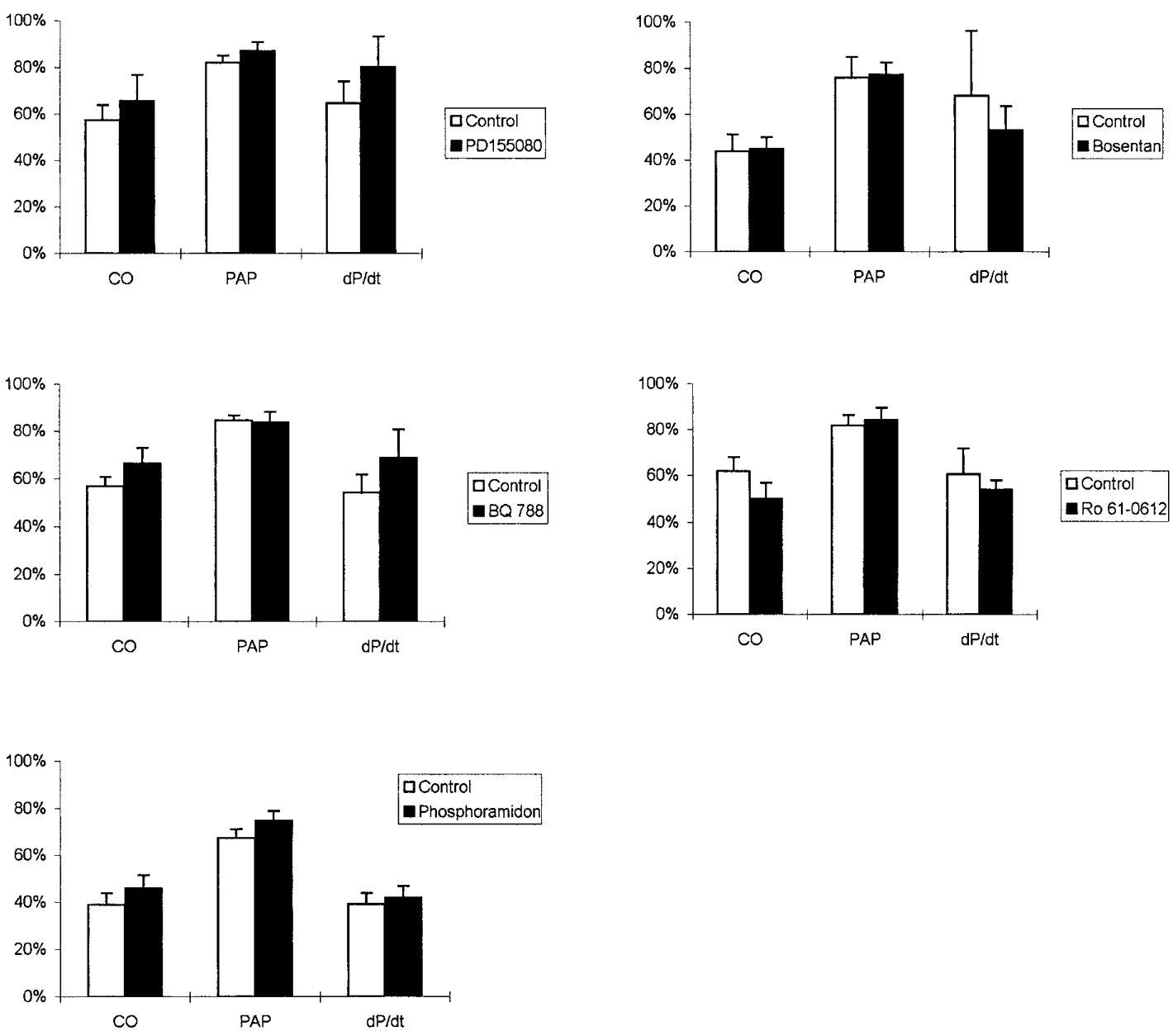

Figure 4. Effect of different ET antagonists and phosphoramidon given during reperfusion on the recovery of cardiac mechanical function after 4 hours' cardioplegic arrest. CO, Cardiac output; PAP, peak aortic pressure.

the levels of the other metabolites measured between the 2 groups.

\section{Discussion}

This study has shown that the recovery of CF is significantly improved after the addition of an ET antagonist during reperfusion. We have demonstrated that both the mixed $\mathrm{ET}_{\mathrm{A}} / \mathrm{ET}_{\mathrm{B}}$ antagonists and selective $\mathrm{ET}_{\mathrm{A}}$ antagonists had a beneficial effect, whereas the $\mathrm{ET}_{\mathrm{B}}$ antagonist had no effect. This suggests that endogenous ET plays a significant role in the regulation of coronary tone during reperfusion and that these effects are mediated through $\mathrm{ET}_{\mathrm{A}}$ receptors. In addition, there was a significant increase in ATP levels by $12 \%$ after reperfusion with an $\mathrm{ET}_{\mathrm{A}} / \mathrm{ET}_{\mathrm{B}}$ antagonist. Despite the improvement in CF and ATP levels, we were unable to demonstrate any beneficial effect on the recovery of cardiac mechanical function in this model.

A number of investigators have suggested that basal vascular tone may be due to a balance between the release of vasoconstrictor and vasodilator substances by the endothelium. ${ }^{1,18-21}$ We have previously demonstrated that endogenous ET plays a role in the basal regulation of coronary tone in the isolated rat heart mediated through $\mathrm{ET}_{\mathrm{A}}$ receptors. ${ }^{1}$ This study has demonstrated for the first time that endogenous ET plays an important role in the regulation of coronary tone during reperfusion. In the experiments with phosphoramidon (ECE inhibitor), there was no effect on $\mathrm{CF}$, despite a prolonged period of reperfusion, suggesting that de novo ET synthesis during reperfusion does not appear to play a role in this model. ET levels are increased after warm ischemia, ${ }^{5}$ whereas there was no increase in ET release from lambs' hearts after 2 hours of hypothermic cardioplegic arrest, suggesting that ET synthesis may not be possible during ischemia at low temperatures. ${ }^{22}$ However, we have shown previously that an ECE inhibitor given during ischemia can improve the postischemic recovery of CF. ${ }^{12}$ These differing results may be due to the different animal models and ischemic protocols studied. 
A number of previous studies have used ET antagonists to examine the role of ET-1 during ischemia and reperfusion. The results of these studies have been conflicting. Some studies have shown a beneficial effect on the recovery of cardiac function, ${ }^{22-26}$ whereas others have not. ${ }^{11,27}$ Some studies have shown improvement in the recovery of CF but not in function. ${ }^{12}$ One possible explanation is that ET blockade removes both the beneficial (positive inotrope) and detrimental (vasoconstriction) effects of ET released during and after ischemia. ET release during ischemia occurs in all mammalian species studied, including human subjects. Therefore, it is probable that there is a beneficial role for ET during ischemia and reperfusion. Possible roles are the maintenance of systemic blood pressure during acute hemorrhagic shock, with the diversion of blood flow away from nonvital organs, and any inotropic effects on the myocardium. Local release of ET may also divert blood flow away from infarcted and necrotic areas of myocardium. It has been shown that the vasoconstrictor effects of exogenous ET-1 are increased after prolonged cold cardioplegic arrest. ${ }^{28}$ It has also been suggested that ET reduces the incidence of malignant cardiac arrhythmias during reperfusion. ${ }^{29,30}$

We have shown that reperfusion with an $\mathrm{ET}_{\mathrm{A}} / \mathrm{ET}_{\mathrm{B}}$ antagonist can improve the recovery of ATP levels after prolonged ischemia and reperfusion. This would imply that the use of an ET antagonist may be expected to be of benefit on cardiac recovery. We were, however, unable to demonstrate any functional benefit of this metabolic change. The majority of studies demonstrate good correlation between ATP level and function, ${ }^{17,31,32}$ but there are situations in which a lack of such correlation has been clearly demonstrated. ${ }^{33}$ It is possible that the observed increase in cardiac ATP levels were insufficient to obtain any measurable benefit. Alternatively, the loss of any direct actions of ET-1 on cardiac function may counteract any beneficial effects seen. Despite the fact that elevated ATP levels did not translate into functional improvement, it is possible that they may provide long-term beneficial effects in vivo by enhancing endogenous adenosine production ${ }^{34}$ and by inhibition of inflammatory and thrombotic mechanisms of reperfusion injury not reproduced in our present experiments.

In experiments with isolated human left ventricular myocytes, exogenous ET increased contractility under basal conditions but reduced contractility after simulated cardioplegic arrest. ${ }^{35,36}$ This would again suggest that ET blockade may be beneficial during reperfusion, even though it was not possible to demonstrate this in our model. Further studies are required in which $\mathrm{CF}$ is maintained at a constant level during reperfusion to distinguish effects caused by improvements in $\mathrm{CF}$ and direct effects on the myocardium of circulating ET.

There are a number of limitations to this study. First, a crystalloid perfused isolated heart does not accurately rep- resent the normal conditions experienced by the heart in vivo. However, the benefits of an isolated system are that it reduces any confounding factors, such as circulating levels of catecholamines, neuronal control, and any effects caused by neutrophil-endothelial cell interactions. Second, this study was performed on rats. Further studies are required to see whether similar effects are seen in human subjects and other animals. Finally, the data may only be applicable to the transplant situation (isolated heart, 4 hours at $4^{\circ} \mathrm{C}$ ), whereas the conditions during routine cardiac operations might differ (collateral $\mathrm{CF}, 1-2$ hours at $10^{\circ} \mathrm{C}$ ).

In summary, we conclude that endogenous ET plays a role in low coronary reflow after prolonged cardioplegic arrest, mediated through $\mathrm{ET}_{\mathrm{A}}$ receptors, in a model mimicking the conditions of preservation during cardiac operations. ET blockade during reperfusion also improves the recovery of high-energy phosphates. These results may have important implications for clinical practice.

We thank Parke-Davis Pharmaceuticals, Ann Arbor, Michigan, and Hoffmann-La Roche, Ltd, Basel, Switzerland, for the donation of the antagonists.

\section{References}

1. Goodwin AT, Amrani M, Gray CC, Jayakumar J, Yacoub MH. Role of endogenous endothelin in the regulation of basal coronary tone in the rat. J Physiol. 1998;511:549-57.

2. Pelc LR, Garancis JC, Gross GJ, Warltier DC. Alteration of endothelium-dependent distribution of myocardial blood flow after coronary occlusion and reperfusion. Circulation. 1990;81:1928-37.

3. Quillen JE, Sellke FW, Brooks LA, Harrison DG. Ischemia-reperfusion impairs endothelium-dependent relaxation of coronary microvessels but does not affect large arteries. Circulation. 1990;82:586-94.

4. Amrani M, Chester AH, Jayakumar J, Schyns CJ, Yacoub MH. LArginine reverses low coronary reflow and enhances postischaemic recovery of cardiac mechanical function. Cardiovasc Res. 1995;30: 200-4.

5. Miyauchi T, Yanagisawa M, Tomizawa T, et al. Increased plasma concentrations of endothelin- 1 and big endothelin-1 in acute myocardial infarction. Lancet. 1989;2:53-4.

6. Watanabe T, Suzuki N, Shimamoto N, Fujino M, Imada A. Endothelin in myocardial infarction. Nature. 1990;344:114.

7. Watanabe T, Suzuki N, Shimamoto N, Fujino M, Imada A. Contribution of endogenous endothelin to the extension of myocardial infarct size in rats. Circ Res. 1991;69:370-7.

8. Tonnessen T, Naess PA, Kirkeboen KA, Offstad J, Ilebekk A, Christensen G. Release of endothelin from the porcine heart after short term coronary artery occlusion. Cardiovasc Res. 1993;27:1482-5.

9. Maulik N, Liu X, Subramanian R, Das DK. Release of endothelin during reperfusion of ischemic myocardium. ET-1 release from reperfused heart. Am J Cardiovasc Pathol. 1992;4:133-44.

10. McMurdo L, Thiemermann C, Vane JR. The effects of the endothelin ETA receptor antagonist, FR 139317, on infarct size in a rabbit model of acute myocardial ischaemia and reperfusion. Br J Pharmacol. 1994; 112:75-80

11. Dagassan PH, Breu V, Clozel M, Clozel JP. Role of endothelin during reperfusion after ischemia in isolated perfused rat heart. $J$ Cardiovasc Pharmacol. 1994;24:867-74.

12. Goodwin AT, Amrani M, Gray CC, Chester AH, Yacoub MH. Inhibition of endogenous endothelin during cardioplegia improves low coronary reflow following prolonged hypothermic arrest. Eur $J$ Cardiothorac Surg. 1997;11:981-7. 
13. Hearse DJ, Stewart DA, Braimbridge MV. Protection of the ischemic myocardium: cardioplegia. New York: Raven Press; 1981.

14. Haynes WG, Webb DJ. Contribution of endogenous generation of endothelin-1 to basal vascular tone. Lancet. 1994;344:852-4.

15. Smolenski RT, Lachno DR, Ledingham SJ, Yacoub MH. Determination of sixteen nucleotides, nucleosides and bases using high-performance liquid chromatography and its application to the study of purine metabolism in hearts for transplantation. $J$ Chromatogr. 1990;527:414-20.

16. Montero C, Smolenski RT, Duley JA, Simmonds HA. S-adenosylmethionine increases erythrocyte ATP in vitro by a route independent of adenosine kinase. Biochem Pharmacol. 1990;40:2617-23.

17. Jayakumar J, Smolenski RT, Gray CC, et al. Influence of heat stress on myocardial metabolism and functional recovery after cardioplegic arrest: a 31P N.M.R study. Eur J Cardiothorac Surg. 1998;13:467-74.

18. Luscher TF, Tanner FC. Endothelial regulation of vascular tone and growth. Am J Hypertens. 1993;6:283S-93S.

19. Rubanyi GM. Endothelium-derived relaxing and contracting factors. $J$ Cell Biochem. 1991;46:27-36.

20. Stewart DJ. Role of EDRF and endothelin in coronary vasomotor control. Basic Res Cardiol. 1991;86(Suppl 2):77-87.

21. Rubanyi GM. Maintenance of "basal" vascular tone may represent a physiological role for endothelin. J Vasc Med Biol. 1989;1:315-6.

22. Hiramatsu T, Forbess J, Miura T, Roth SJ, Cioffi MA, Mayer JE Jr. Effects of endothelin-1 and endothelin-A receptor antagonist on recovery after hypothermic cardioplegic ischemia in neonatal lamb hearts. Circulation. 1995;92(Suppl):II-400-4.

23. Han H, Neubauer S, Braeker B, Ertl G. Endothelin-1 contributes to ischemia/reperfusion injury in isolated rat heart-attenuation of ischemic injury by the endothelin-1 antagonists BQ123 and BQ610. $J$ Mol Cell Cardiol. 1995;27:761-6.

24. Li XS, Wang QD, Pernow J. Beneficial effects of the endothelin receptor antagonist bosentan on myocardial and endothelial injury following ischaemia/reperfusion in the rat. Eur J Pharmacol. 1995;283:161-8.

25. Okada K, Yamashita C, Okada M. Efficacy of oxygenated University of Wisconsin solution containing endothelin-A receptor antagonist in twenty-four-hour heart preservation. J Heart Lung Transplant. 1996; 15:475-84.
26. Illing $\mathrm{B}$, Horn $\mathrm{M}$, Han $\mathrm{H}$, et al. Protective effect of the specific endothelin-1 antagonist BQ610 on mechanical function and energy metabolism during ischemia/reperfusion injury in isolated perfused rat hearts. J Cardiovasc Pharmacol. 1996;27:487-94.

27. McClanahan TB, Mertz TE, Ignasiak DP, Juneau PL, Gallagher KP. Effects of endothelin-receptor antagonism with PD156707 on myocardial stunning in swine. J Cardiovasc Pharmacol. 1996;28:679-86.

28. Goodwin AT, Amrani M, Marchbank AJ, Gray CC, Jayakumar J, Yacoub MH. Coronary vasoconstriction to endothelin-1 increases with age before and after ischaemia and reperfusion. Cardiovasc Res. 1999;41:554-62.

29. Vitola JV, Forman MB, Holsinger JP, et al. Role of endothelin in a rabbit model of acute myocardial infarction: effects of receptor antagonists. J Cardiovasc Pharmacol. 1996:28:774-83.

30. Woodcock EA, Reyes N, Jacobsen AN, Du XJ. Inhibition of inositol $(1,4,5)$ triphosphate generation by endothelin-1 during postischemic reperfusion. A novel antiarrhythmic mechanism. Circulation. 1999;99:823-8.

31. Steenbergen C, Murphy E, Watts JA, London RE. Correlation between cytosolic free calcium, contracture, ATP, and irreversible ischemic injury in perfused rat heart. Circ Res. 1990;66:135-46.

32. Swain JL, Hines JJ, Sabina RL, Holmes EW. Accelerated repletion of ATP and GTP pools in postischemic canine myocardium using a precursor of purine de novo synthesis. Circ Res. 1982;51:102-5.

33. Kupriyanov VV, Lakomkin VL, Kapelko VI, Steinschneider AY, Ruuge EK, Saks VA. Dissociation of adenosine triphosphate levels and contractile function in isovolumic hearts perfused with 2-deoxyglucose. J Mol Cell Cardiol. 1987;19:729-40.

34. Smolenski RT, Kalsi KK, Zych M, Kochan Z, Yacoub MH. Adenine/ribose supply increases adenosine production and protects ATP pool in adenosine kinase-inhibited cardiac cells. $J$ Mol Cell Cardiol. 1998;30:673-83.

35. Goldberg AT, Bond BR, Mukherjee R, et al. Endothelin receptor pathway in human left ventricular myocytes: relation to contractility. Ann Thorac Surg. 2000;69:711-6.

36. Dorman BH, New RB, Bond BR, et al. Myocyte endothelin exposure during cardioplegic arrest exacerbates contractile dysfunction after reperfusion. Anesth Analg. 2000;90:1080-5.

\section{Authoritative}

The Journal of Thoracic and Cardiovascular Surgery is the most frequently cited thoracic/cardiovascular surgery journal in the Science Citation Index. An article in JTCVS is sited on average almost twice as often as those in the closest cardiothoracic journal. 